\title{
Ensaio Metodológico para a Prospecção Mercadológica para Empreendimentos Gastronômicos ${ }^{1}$
}

\author{
Methodological Essay for the Gastronomy Enterprising Market Prospecting
}

\author{
Regina Ferraz Perussi ${ }^{2}$ \\ Reinaldo Miranda de Sá Teles ${ }^{3}$
}

\begin{abstract}
Resumo
Este estudo aborda os principais passos que abrangem a prospecção mercadológica para a abertura de estabelecimentos gastronômicos inserida no contexto de destinos turísticos. Tal processo de pesquisa foi dividido em quatro partes: Empresa (produtos e serviços); Mercados (demanda ou público alvo); Setor Financeiro e Estratégias de Comunicação. O roteiro para a criação de um novo estabelecimento teve como base os critérios estabelecidos pelo Planejamento Estratégico, apoiados em objetivos, metas e a missão da empresa. Foram contemplados temas relacionados à uma prática que vai de encontro à teoria dos 4 Ps (Produto, Preço, Ponto e Propaganda), envolvendo os aspectos que compõem o processo evolutivo de uma empresa do setor de Alimentos e Bebidas. As reflexões foram indicadoras da importância de se estabelecer etapas e parâmetros no processo de idealização não só para a implantação, mas sobretudo para a gestão de empreendimentos na área gastronômica
\end{abstract}

Palavras-chave: prospecção mercadológica; planejamento estratégico; empreendedorismo; gastronomia; destinos turísticos.

\section{Abstract}

This paper broaches the main steps that approaches the market prospecting for the gastronomy stores opening inserted on the context of tourist destinations. This survey process was shared in four parts: Company (products and services); Markets (demanding or tagging

\footnotetext{
1 Trabalho apresentado no DAC 3 - Divisão Científica Ambiente, Cultura e Sociedade em Turismo e Hospitalidade VI ANPTUR, realizado no período de 10 e 11 de setembro de 2009 na Universidade Anhembi Morumbi.

${ }^{2}$ Mestre e Bacharel em Turismo pela Escola de Comunicações e Artes da Universidade de São Paulo; Docente no campus SENAC São Paulo nos Cursos de Bacharelado em Turismo, Tecnologia em Turismo e Tecnologia em Gastronomia. No mercado de Turismo atua como consultora de Viagens autônoma. Pesquisadora do grupo de pesquisa "Análise Mercadológica das agencias de viagens e operadoras de Turismo". Email: reginaferraz.perussi@gmail.com.

${ }^{3}$ Doutor em Ciências da Comunicação e Mestre em Lazer e Turismo pela Escola de Comunicações e Artes da Universidade de São Paulo; Bacharel em Geografia pela Faculdade de Filosofia, Letras e Ciências Humanas da Universidade de São Paulo; licenciado em Geografia pela Faculdade de Educação da Universidade de São Paulo. Docente do Curso de Graduação em Turismo, da Escola de Comunicações e Artes da Universidade de São Paulo. Email: reiteles@usp.br.
} 
costumer); Financial Sector and Communication Strategies. The guide for the new store creation had the established Strategic Plannig criteria as a basis, sustained in objectives, goals and company mission. The related issues were contemplated in a practice related to the Four P's Theory (Product, Price, Place and Promotion), involving the composing aspects that constitutes one food and liquor company evolutive process. The reflections were indicative of the importance of establishing stages and parameters in the idealization process, not only for the implanting, but also to the management of enterprises in the gastronomy area.

Keywords: market prospecting; strategic planning; enterprising; gastronomy, tourist destinations.

\section{Introdução}

É possível afirmar que nos últimos anos tem havido significativo crescimento de empresários no ramo do Turismo e, em especial, no setor da gastronomia. Verifica-se cada vez mais, expressivo número de pequenos investidores que aderem a diferentes propostas voltadas à restauração. Conforme destaca Shaw (2004, p. 147) na maior parte das economias do Turismo, o aumento de organizações de grande porte e da sua crescente participação de mercado apresenta-se em contraste com a importância numérica das pequenas empresas, cuja operação coletiva tem sido pouco enfocada no contexto dos destinos turísticos. Uma exceção refere-se à uma pesquisa feita sobre redes inter-empresas e parcerias na área do turismo e de alimentos e bebidas, de acordo com Hall et all. (2000 e 2003) apud Shaw (2004, p. 156). Neste contexto, uma série de estudos demonstrou a importância das redes de pequenos negócios em destinos específicos, como aponta Telfer (2000, p. 156) apud Shaw (2004, p.156). Nestas condições, a concorrência e a cooperação estão lado a lado, pois ao mesmo tempo em que os estabelecimentos de hospedagem concorrem na procura de turistas, também cooperam com a comercialização do destino.

Desta forma, a proposta deste ensaio é apresentar uma sugestão de roteiro para a abertura de pequenos empreendimentos na área de Gastronomia de forma a contribuir para uma melhor oferta de destinações turísticas, com as principais etapas do que se denomina de Prospecção Mercadológica. Segundo o dicionário Houaiss (2001, p. 2.315) prospecção significa “o conjunto de técnicas relativas à pesquisa, sondagem, localização precisa e estudo preliminar; olhar adiante, procurar e buscar o futuro". Logo, esta prospecção voltada para o mercado 
possibilita conceituar, conceber, organizar, pesquisar, analisar, viabilizar e comercializar produtos e serviços da gastronomia adequados aos interesses, hábitos, atitudes e expectativas do ramo de alimentos e bebidas e, por conseguinte, da hospitalidade das localidades.

A estrutura desta Prospecção Mercadológica foi elaborada segundo o modelo proposto por Mattar (1997), porém adaptado para os serviços gastronômicos. Assim, o escopo do trabalho será dividido em quatro partes: Empresa (produtos e serviços); Mercados (público alvo); Setor Financeiro e Estratégias de Comunicação.

\section{Empresa (produtos e serviços)}

O primeiro passo para a criação do futuro empreendimento refere-se à definição de sua caracterização conforme sua especialização, como, por exemplo, restaurante, bar, lanchonete, cafeteria, dentre outras opções ${ }^{4}$. Posteriormente, deve ser verificada a classificação do novo estabelecimento, de acordo com o valor pago pelos clientes, como quick service restaurant, midscale, moderate upscale ou upscale ${ }^{5}$, além do tipo de culinária a ser trabalhada (brasileira, italiana, japonesa, francesa, etc.), bem como os serviços a serem oferecidos (café da manhã, almoço, chá da tarde, jantar, coquetel, coffee break).

A seguir, é preciso determinar os dias e horários de funcionamento do projeto construtivo, o que irá estabelecer turnos dos colaboradores, os tipos de serviços e os preços a serem cobrados, com o consequente planejamento da mise en place ${ }^{6}$ do salão e da cozinha.

A próxima etapa diz respeito à procura pelo local da instalação da empresa, o que é um fator determinante para a abertura e o sucesso da mesma. Neste sentido, o "Ponto ou Praça” deverá

\footnotetext{
${ }^{4}$ Segundo Fonseca (2004, p. 20-34), de modo geral, pode-se considerar os estabelecimentos como restaurantes, dividindo-os em tradicional, internacional, gastronômico e de especialidades. Destes últimos, os mais comuns são: grill, brasserie, choperia, fusion food, típicos (de acordo com país, região e gênero), fast food (coffee shop, lanchonete, casual dining e self service) e restaurantes de coletividades (como catering e buffet). Além destes, pode-se considerar outros tipos, como casa noturna, rotisserie, casa de chá, doçaria, sorveteria, pub, drugstore e casa de sucos e vitaminas.

${ }^{5}$ Conforme Muller \& Woods (1994, p. 27-36) esta classificação se refere à estratificação pelo fator preço, sendo que o quick service restaurant seria um estabelecimento do tipo econômico, o midscale se refere ao familiar, o moderate upscale significa um empreendimento moderado, ao passo que o upscale está relacionado ao luxo.

${ }^{6}$ Mise en place é uma expressão de origem francesa que significa "arrumação, colocação em ordem". Logo, tanto para o restaurante ou sala, engloba o conjunto de trabalhos previamente executados para colocar o local, os objetos ou alimentos e bebidas em ordem.
} 
atender em primeira instância às normas exigidas pela Lei de Zoneamento do Município. Para tanto, deve-se consultar as prefeituras locais para verificar se a localidade permite o funcionamento de estabelecimentos comerciais na atualidade, ressaltando que um logradouro pode ter tido suas regras alteradas ao longo tempo. Ao se encontrar um imóvel construído disponível para a compra ou locação, deve-se buscar o apoio de imobiliárias para se conhecer suas "plantas" e dimensões. Aliado a isso, com o conhecimento do espaço disponível, a projeção da capacidade máxima de atendimento ou o número de assentos se apresenta como essencial, especialmente no caso da realização de Eventos no local, em que poderá existir um remanejamento da distribuição de mesas e cadeiras.

Por outro lado, nesse processo de escolha não se pode negligenciar as tendências urbanísticas de cada localidade e procurar detectar zonas ou bairros que possuem concorrência direta ou indireta. Para empreendimentos com o mesmo produto, é preciso investigar se mais uma nova empresa no ramo poderá significar uma concorrência demasiada ou uma oportunidade para constituir uma "região temática", ou ainda, pode representar como uma possibilidade de se atingir um nicho de mercado em uma área pouco explorada por certo tipo de empresa gastronômica.

A base para montar um novo estabelecimento deve obrigatoriamente incluir uma pesquisa dos concorrentes, pois pode-se acreditar que uma proposta seja inovadora em algum aspecto e este produto ou serviço já existir no mercado. Para esta investigação de campo, deve-se registrar e comparar os seguintes critérios: especialidade da culinária, ano da abertura, dias e horários de funcionamento, número de assentos, distância em relação ao estabelecimento a ser implantado, perfil do público frequentador, tempo de permanência média, couvert médio ${ }^{7}$, ambientação, existência de som (música ambiente ou ao vivo ou ainda ruídos no local), logística e tempo de serviço (dias e horários padrão em comparação com os períodos de pico), cardápio (principalmente o "carro chefe"), limpeza, diferenciais e pontos fracos, existência de serviços de bar e eventos, estacionamento próprio ou serviço de vallet com manobristas, média de couverts diários; dados sobre a brigada (tamanho, cargos e funções e uso/tipos de uniformes), além da verificação da existência de programas de fidelização. Além disso, uma

\footnotetext{
${ }^{7} \mathrm{O}$ couvert médio se refere à média de gastos dos clientes em um restaurante, mencionados na fatura final.
} 
lista com nomes, produtos e preços praticados pelos fornecedores apresenta-se como um requisito essencial nesta fase de planejamento.

Além da fachada, Maricato (2004, p.104-106) menciona a preocupação com a decoração interna, que deve estar relacionada com a temática ou proposta do local, de maneira a criar uma ambientação de destaque por meio da escolha do tipo de mobília, a existência de sonorização, o modo de ventilação (natural ou por meio de ventiladores ou ar condicionados) e iluminação (recinto aberto ou fechado, intensidade da luz) desde as cores até os objetos de exposição. Já o SENAC (2006, p.52-58) acrescenta que é preciso lidar com os seguintes espaços: cozinha, almoxarifado, salão, toaletes, gerência, além da questão do lixo.

Para a organização de qualquer novo empreendimento, é imprescindível seguir as orientações do Planejamento Estratégico orientado para o mercado, que para Kotler (2000, p. 86):

(...) é o processo gerencial de desenvolver e manter um ajuste viável entre objetivos, habilidades e recursos de uma organização e as oportunidades de um mercado em contínua mudança. $\mathrm{O}$ objetivo do planejamento estratégico é dar forma aos negócios e produtos de uma empresa, de modo que eles possibilitem os lucros e o crescimento almejados.

A base de um planejamento estratégico diz respeito aos objetivos, entendidos como resultados finais de um projeto e as metas como os objetivos quantificados, com prazos estabelecidos.

O estabelecimento da missão ou conceito empresarial também se faz importante, segundo Karlof (1994, p.133), pois se trata da oportunidade de fazer negócios que uma empresa identifica no contexto, envolvendo consumidores, produtos e margem competitiva. O conceito de missão empresarial passou a ser muito corrente como parte importante da base ideológica ou cultura de uma organização. Em geral, é utilizado para se chegar a um entendimento básico e à uma visão holística das relações empresariais. Uma missão empresarial tem grande valor comunicativo, tanto internamente, ao esclarecer os objetivos empresariais aos empregados, como externamente, através da informação aos acionistas, fornecedores e consumidores.

De encontro à essa proposição, é imprescindível a projeção de um Diagnóstico, que consiste na análise interna e externa da empresa, também conhecida como análise macroambiental 
com a sigla $\mathrm{SWOT}^{8}$. A análise interna se relaciona aos aspectos da própria empresa, tais como sua estrutura física, operacional, administrativa e financeira, visando detectar as vantagens competitivas que serão destacadas na divulgação, além dos pontos fracos que devem ser corrigidos ou amenizados. Por outro lado, devem ser verificados os elementos que a empresa não possui controle, pois fazem parte de seu ambiente externo, como as oportunidades e as ameaças, que são situações momentâneas que a empresa deve, respectivamente, tentar aproveitar ou evitar por meio de estratégias de planejamento. Para Kotler (2000, p.100) cada empresa precisa fazer uma investigação constante de suas forças e fraquezas internas, classificando cada um desses elementos presentes nos seus diversos departamentos organizacionais como "uma grande força, uma força, uma característica neutra, uma fraqueza ou uma grande fraqueza". Tal autor entende ainda que "uma oportunidade existe quando a empresa pode lucrar ao atender às necessidades dos consumidores de um determinado segmento" e "uma ameaça ambiental é um desafio imposto por uma tendência ou desenvolvimento desfavorável que levaria, na ausência de uma ação de marketing defensiva, à deterioração das vendas ou dos lucros". (KOTLER, 2000, p. 98-99)

Após a análise da situação atual, a elaboração do prognóstico é de vital relevância, visto que envolve a estruturação de cenários futuros, que na realidade são possibilidades de situações que podem ocorrer com a empresa no porvir. Para Porter (1986, p. 94):

(...) um cenário é uma visão internamente consistente do que o futuro poderá vir a ser, e tem como principais funções a avaliação explícita de premissas de planejamento, o apoio à formulação de objetivos e estratégias, a avaliação de alternativas, o estímulo à criatividade, a homogeneização de linguagens e a preparação para enfrentar descontinuidades.

Sendo assim, a principal finalidade é fazer com que a organização esteja preparada para enfrentar possíveis obstáculos e mudanças repentinas que possam inclusive levá-la à falência, tendo de antemão soluções direcionadas. Para tanto, o método indicado é a seleção de dois fatores relevantes para a empresa detectados na Análise SWOT relacionados em quatro quadrantes com sinais positivo e negativo alternados, para que se possa verificar hipóteses de

\footnotetext{
${ }^{8}$ A sigla SWOT em inglês significa "Stenghts" - forças ou pontos fortes; "Weaknesses" - fraquezas ou pontos fracos; "Opportunities" - oportunidades e "Threats" - ameaças.
} 
ocorrência no futuro e a identificação de cenários prováveis e possíveis (realistas), negativos (pessimistas) e desejáveis (otimistas) com as indicações de propostas de intervenções práticas para cada possibilidade, caso a mesma venha a se concretizar posteriormente (PERUSSI, 2008, p. 199).

A projeção das possíveis etapas de desenvolvimento evolutivo da empresa é outro elemento relevante neste processo de planejamento. Para Butler (1980, p. 8) o ciclo de vida de destinos turísticos pode ser dividido em seis estágios: exploração, envolvimento, desenvolvimento, consolidação, estagnação e renovação ou declínio. Tais fases foram adaptadas pelos autores deste estudo para o produto gastronômico. Pode-se considerar que a primeira etapa da exploração refere-se à prospecção mercadológica, que consiste exatamente no cerne desta pesquisa, já que propõe a investigação dos elementos necessários para a abertura de um novo empreendimento. Após a inauguração, é o momento de concentrar esforços no crescimento e desenvolvimento do estabelecimento, entendendo-se que pode ocorrer uma expansão do espaço, do quadro de funcionários ou do cardápio, e/ou um aperfeiçoamento da estrutura já implantada por meio de melhorias na decoração, investimento em treinamento dos colaboradores ou adaptação dos pratos conforme a percepção dos gostos da clientela. A chegada da consolidação pode ser marcada pela quitação dos gastos com a implantação, a superação do ponto de equilíbrio com os primeiros frutos de lucratividade, o reconhecimento do estabelecimento na mídia especializada e/ou pela sociedade em geral, com uma significativa taxa de ocupação e solicitação de reservas antecipadas. Este estágio da maturidade pode ser considerado como o mais almejado, porém o mais perigoso, pois pode levar à uma acomodação dos proprietários ou gestores. Se não houver uma preocupação constante com a manutenção dos índices de excelência na qualidade que propiciaram o ápice, o estabelecimento pode chegar ao declínio, onde se percebe uma diminuição do número de comensais em virtude de diversos fatores. Se providências não forem tomadas a tempo, podese alcançar o estágio de estagnação, onde o encerramento das atividades está próximo. Sendo assim, é que se propõe que a revitalização seja um processo constante desde a abertura do empreendimento, com contínuas pesquisas de mercado, detectando sempre novos nichos de mercado e tendências do ramo. 
Uma outra questão significativa para o planejamento de estabelecimentos gastronômicos se refere fundamentalmente à elaboração de seu cardápio. A sua adequada formatação deve prever duas questões: a montagem dos itens do menu, de preferência com poucas opções, com foco na qualidade e na apresentação dos pratos, atrelado ao seu layout, que "deve ter um formato original e ser bonito, limpo e fácil de manusear, com o logotipo do restaurante na capa [...] as letras do menu devem ser legíveis [...] a diagramação deve facilitar a escolha dos pratos, agilizando o pedido" (MARICATO, 2004, p.92).

Além do cardápio, é preciso verificar se de acordo com o estilo do empreendimento, o couvert médio e o perfil do público-alvo é exigida a elaboração de uma carta de vinhos, pois segundo Pacheco (2006, p.88) “a carta de vinhos, assim como o cardápio ou o menu, é o cartão de visita do restaurante, e é neles que o cliente conhece a seriedade do estabelecimento".

Maricato (2004, p. 109-110) entende que "um bom serviço de vinhos, com opções razoáveis e uma bela adega, pode proporcionar ganhos ao estabelecimento, tanto financeiros quanto de fidelização do cliente [...] Além disso, o vinho atrai clientes de alto poder aquisitivo e contribui para aumentar o consumo por pessoa".

Quanto à apresentação e composição da carta de vinhos, Pacheco (2006, p.88) recomenda que:

[...] deve ser concisa, atraente, bem diagramada, de tamanho médio, cores agradáveis, conteúdo bem distribuído e em letras com tamanho e formato legíveis. Deve conter, além de vinhos brasileiros, os vinhos estrangeiros que mais se consomem no Brasil, e vinhos de diversos sabores, cores e preços, para permitir diversas opções aos clientes.

Outra questão que se encontra bastante em voga em Gastronomia diz respeito à Enogastronomia ou harmonização, ou seja "fazer com que vinhos e comidas se fundam, se completem, se equilibrem [...] pela combinação de sabores, com a intenção de explorar ao máximo as possibilidades de apreciação da bebida e das iguarias, potencializando seus valores", conforme aponta Novakoski e Freire (2005, p. 29) Neste sentido, é preciso se atentar a este aspecto, que pode se constituir, em alguns casos, em um importante diferencial do estabelecimento. 
Com a oferta do empreendimento devidamente estruturada, parte-se para a investigação da futura clientela.

\section{Mercados, Demanda ou Público-Alvo}

O conhecimento do perfil do público que se deseja atrair e manter é estratégico, pois mesmo com um mercado globalizado, não se consegue atingir as expectativas de todos os grupos da sociedade. Por esta razão, é preciso conhecer a clientela conforme a proposta do estabelecimento e de uma forma mais detalhada, o que só é possível por meio da aplicação dos critérios de segmentação da demanda. Tal processo consiste em dividir os grupos de pessoas com características semelhantes em segmentos ou nichos (sub-segmentos) para melhor atender aos seus anseios. Assim, Kotler e Armstrong (2003, p.177-183) sugerem quatro variáveis de segmentação.

- Segmentação geográfica - consiste na divisão do mercado em diferentes unidades geográficas. Neste aspecto, deve-se levar em conta a origem dos clientes do estabelecimento;

- Segmentação demográfica e socioeconômica - analisa as características objetivas das pessoas de uma determinada localidade por meio de estatísticas. É baseada nos critérios de gênero, faixa etária, estado civil, grau de instrução, profissão ou ocupação, renda ou classe social, religião, etnia, nacionalidade, etc.;

- Segmentação psicográfica ou de personalidade - indica a separação dos consumidores por estilo de vida, prática de atividades, interesses, hobbies e valores;

- Segmentação por benefício - está relacionada com as vantagens que os consumidores buscam em uma determinada categoria de produto ou serviço, como status ou prestígio social, maior qualidade, melhor atendimento, economia, rapidez na prestação dos serviços, marcas conhecidas, produtos naturais, dentre outros fatores.

Diante do perfil do público-alvo, é preciso estabelecer parâmetros de manutenção dessa clientela a longo prazo, estreitando-se os laços com os clientes, que representam o principal patrimônio da empresa, sendo essencial o investimento em programas de fidelização. $\mathrm{Na}$ área 
de Gastronomia buscar a exclusividade pode se tornar uma tarefa quase impossível, tendo em vista a diversidade de estabelecimentos e especializações. No entanto, para determinados tipos de culinária ou empreendimentos pode-se encontrar comensais exclusivos, principalmente para o público mais tradicional ou que não está em constante busca de inovação. Embora esse desafio seja árduo, deve ser perseguido porque a lucratividade das empresas depende desta estratégia de mercado. Neste contexto, o marketing de relacionamento ou $\mathrm{CRM}^{9}$ de acordo com Swift (2001, p.12) "é uma abordagem empresarial destinada a entender e influenciar o comportamento dos clientes, por meio de comunicações significativas para melhorar as compras, a retenção, a lealdade e a lucratividade deles". A formação de um banco de dados com as principais características da clientela auxilia no acompanhamento das alterações dos hábitos e preferências da demanda ao longo do tempo e consequentemente norteia as mudanças exigidas na estrutura física ou no serviço. No entanto, para atender às exigências da demanda, é preciso investir, o que implica em questões financeiras e, portanto, não há como se abordar a projeção de um novo empreendimento sem considerar as suas receitas e despesas.

\section{Financeiro}

Para que um negócio seja sustentável e lucrativo a longo prazo, a apurada gestão no cálculo dos preços deve estar calcada no controle de custos por meio das despesas fixas e variáveis e na formação de preços, conforme atesta SENAC (2006, p. 77). É possível afirmar que, diante da competitividade verificada no mercado o preço pode se transformar numa ferramenta estratégica, uma das chaves de sucesso do empreendimento. Conforme destaca o manual do SEBRAE "SABOR \& GESTÃO, 2008”, embora o preço de um produto gastronômico (aqui entendido como um prato do cardápio) seja indicador da soma do que foi gasto para produzilo e vendê-lo e do valor que se atribui ao serviço agregado, ou em outras palavras, o lucro; não se pode fugir dos valores cobrados pela concorrência. Para o SEBRAE (2009), dois aspectos são fundamentais na definição do preço de venda de um produto, o financeiro (interno) e o mercadológico (externo). A tabela a seguir define essas duas condições:

\footnotetext{
9 As iniciais da sigla se relacionam a "Customer Relationship Management", que em português quer dizer "Gerenciamento da Relação com o Cliente".
} 


\begin{tabular}{|l|l|}
\hline \multicolumn{1}{|c|}{ Finanças } & \multicolumn{1}{|c|}{ Mercado } \\
\hline O preço de venda deverá cobrir: & $\begin{array}{l}\text { O preço de venda deverá considerar: } \\
\text {-As despesas variáveis (matéria-prima, } \\
\text { impostos, comissões etc.) } \\
\begin{array}{l}\text {-O custo direto da mercadoria (matéria- } \\
\text { prima, impostos, comissões etc.) }\end{array}\end{array}$ \\
$\begin{array}{l}\text {-As despesas fixas (aluguel, telefone, } \\
\text { salários, pró-labore etc.) A sobra disso será } \\
\text { o lucro líquido. }\end{array}$ & $\begin{array}{l}\text { (no caso de prodo da concorrência } \\
\text { mercado.) }\end{array}$ \\
\hline
\end{tabular}

Fonte dos dados da tabela: SEBRAE“ SABOR \& GESTÃO, 2008

Após a definição do produto gastronômico e o entendimento de que os preços são compatíveis com o mercado ou ao menos são facilmente entendidos pelos diferenciais agregados ao produto, deve-se pensar no retorno financeiro e partir para etapa seguinte.

Para se atingir este retorno financeiro, algumas questões devem ser observadas. Balanzá e Nadal (2003) sugerem algumas estratégias de precificação de produtos para empresas que são especificamente do ramo turístico, mas que podem ser adaptadas para as corporações do ramo gastronômico, considerando que ambas fazem parte do setor de hospitalidade e estão intrinsecamente relacionadas, tais como facilidades de pagamento como vale-refeições e cartões de débito ou crédito; concessão de descontos por volume (em casos de um evento específico pelo número de convidados); variações de tarifas conforme a sazonalidade (como no almoço ou jantar ou então nos dias da semana ou finais de semana); preço psicológico (valores do cardápio em algarismos finais 8 ou 9, que sugerem uma redução do valor real); preço combinado (como menu do dia, incluindo entrada, prato principal e sobremesa ou os "combos" dos fast foods); preço por tipo de serviço (sistema buffet self service, por quilo ou empratado), além das vantagens em função da participação nos programas de fidelização.

Outro aspecto significativo que interfere na parte financeira da empresa se refere à estruturação do Organograma Hierárquico, que irá apresentar a descrição de cargos e funções dos colaboradores. Este item se apresenta como essencial à medida que indicará a necessidade de quantidade e especialização de funcionários no processo de recrutamento e seleção, além da posterior capacitação, o que irá impactar diretamente nas despesas organizacionais. 
O estabelecimento de preços está intimamente atrelado ao público-alvo e ao posicionamento estratégico da organização em seu mercado de atuação. De modo geral, há uma relação entre preços e qualidade, pois o cliente pode optar pela menor tarifa ou o "preço prêmio", quando se tem consciência de pagar mais caro em função dos valores agregados. Kotler (2000, p. 485-489) aponta que dentro da faixa de preços possíveis, a empresa deverá levar em consideração para o estabelecimento de seus preços os custos de produção, os valores dos concorrentes e a avaliação da singularidade do produto. Essa condição irá direcionar para uma estratégia de comunicação voltada ao tipo de empreendimento que se pretende implantar.

\section{Comunicação}

A fim de informar a existência do novo estabelecimento para os consumidores, é preciso implementar ferramentas para estabelecer um canal de comunicação. Uma das formas de se averiguar o seu grau de satisfação da demanda real é a aplicação de um questionário de avaliação comumente denominado de "opinário", que também serve como uma maneira de obtenção e atualização de dados cadastrais, detectando suas críticas e sugestões quanto a produtos oferecidos (comida/bebida ou cardápio e carta de vinhos), ambiente, limpeza e serviço/atendimento.

Neste momento, é primordial a pesquisa dos tipos de mídias com os respectivos preços, dias e horários de veiculação, conforme a proposta do estabelecimento e seu público-alvo. Maricato (2004, p.121-153) menciona como principais formas de divulgação para empreendimentos gastronômicos o jornal da empresa, a mala direta, o telemarketing, as relações públicas, o outdoor, o merchandising, o marketing cooperado (ou recíproco), a assessoria de imprensa, os anúncios em jornais, revistas, rádio e televisão, além da Internet. Por outro lado, indica o interior do estabelecimento como espaço privilegiado de comunicação, bem como a opinião de jornalistas e críticos de gastronomia, sobretudo em guias especializados da área.

A criação de um domínio na Internet com a estruturação de um website, sobretudo da sua homepage e os diversos links é outra maneira de apresentar o produto de forma globalizada.

Reedy et all. (2001, p. 212-215) evidenciam que o planejamento de um site envolve a análise, o design e a construção com foco no público alvo, o conteúdo e a estrutura dos links. A 
aparência do site e a sensação que deve transmitir ao usuário envolvem uma estrutura eficiente e funcional que transmita uma imagem visual e informações esperadas pelo consumidor de forma simples e rápida. Nesse sentido, uma análise empírica de diversos websites de empreendimentos gastronômicos mostrou que muitos itens estão presentes na maioria dos estabelecimentos e outros links nem sempre aparecem na home page, resultando em dúvidas nos frequentadores das empresas de $\mathrm{A} \& \mathrm{~B}$ e até a preferência por estabelecimentos que apresentem sites mais completos em termos de dados e interessantes do ponto de vista ilustrativo.

$\mathrm{Na}$ ótica dos pesquisadores deste artigo, os principais itens a serem inclusos a título de sugestão seriam: o histórico com a missão e/ou a visão do estabelecimento; história do (s) chef(s); dias e horários de funcionamento; serviços oferecidos; endereço com mapa de localização; descrição do cardápio (com ou sem preços); carta de vinhos (se houver); formas de pagamento; fotos (fachada, ambientes internos e pratos, bem como acontecimentos locais) e programação de eventos. Além disso, a possibilidade de se realizar uma visita virtual e uma reserva online é considerada interessante, além de um espaço para contatos (fale conosco e trabalhe conosco - telefone e e-mail), onde se pode receber opiniões e elogios. A posteriori, não se pode deixar de posicionar tal endereço eletrônico nas principais ferramentas de busca da Web.

Percebe-se que alguns elementos são comumente encontrados em páginas eletrônicas de empresas de vários segmentos (localização, fale conosco, trabalhe conosco e histórico) mas outros itens são específicos da área de Gastronomia, como dados sobre o chef de cozinha, cardápio e carta de vinhos.

A confecção de uma peça gráfica de promoção permanente como cartão de visita, folder, prospecto, cartão postal ou flyer é interessante tanto para a divulgação in loco, como também para auxiliar na propagação do estabelecimento em Eventos. No que tange à este quesito, devem ser listados os tipos de acontecimentos com a respectiva quantidade de pessoas, cardápios com fichas técnicas e preços.

Cada empreendedor irá selecionar a melhor forma de comunicar o seu estabelecimento para a sociedade, segundo a proposta temática, a condição financeira e o estilo do público-alvo. 
Por outro lado, a escolha do Nome e da Logomarca é primordial, já que o significado do nome sustenta a Marca da empresa na escala de produtos na mente do consumidor, diferenciando o empreendimento dos seus concorrentes. "Ela identifica, posiciona, comunica, agrega valor, transmite segurança ao cliente, reforça a imagem do produto e revela sua origem" (MARICATO, 2004, p.42). Por isto, a denominação deve ser forte e descritiva, de forma que consiga caracterizar ou classificar o produto gastronômico para os consumidores, remetendo-o à imagem projetada pelos empreendedores.

Portanto, de um modo geral, esta prospecção mercadológica teve como linha condutora os 4 Ps (Produto, Preço, Ponto e Propaganda) ou Mix de Marketing como elementos norteadores das ações estratégicas de mercado.

\section{Considerações Finais}

Este estudo procurou delinear as principais etapas para a abertura de um estabelecimento gastronômico, podendo ser aplicado em empresas de diferentes portes e classificações. O perfil do empreendimento dependerá desde o montante de capital disponível pelo empreendedor e/ou sócios até a escolha particular dos investidores.

No mundo globalizado, a adaptação às novas tendências de mercado permite o alcance de um posicionamento superior à concorrência, com estratégias competitivas que realcem a boa imagem do estabelecimento no seu ramo de atuação.

Além disso, é preciso vincular o nome e a marca da empresa à outras ações e/ou questões consideradas relevantes na sociedade contemporânea, como responsabilidade social e sustentabilidade ambiental, ética e cultural, o que se configura como condição sine qua non para alcançar maior fatia de mercado na conjuntura de competitividade extrema da atualidade.

Sendo assim, o marketing de relacionamento é o requisito fundamental para que se possa conhecer os anseios da demanda e buscar a superação de suas expectativas, a fim de obter sua maior lealdade à Casa. Neste cenário, a customização torna-se uma regra, pois é imprescindível que se busque a personalização dos produtos e do atendimento, fazendo com que cada cliente se sinta diferenciado. 
Os aspectos intangíveis devem permear o ambiente do novo empreendimento, de forma que a sensação de bem-estar propicie uma maior permanência do cliente e seu retorno ao estabelecimento e, em alguns casos, como conseqüência, a um destino turístico específico.

Vale ressaltar que este trabalho é apenas um esboço de um plano de negócios para a abertura de um empreendimento na área de alimentos e bebidas, considerando que o tema Empreendedorismo é amplo e que as pesquisas no ramo de Gastronomia são ainda incipientes. Logo, outras investigações devem ser efetivadas por profissionais do mercado e da academia, a fim de promover um incremento de novos estabelecimentos, sobretudo nas destinações turísticas, contribuindo para uma oferta de excelência com foco na hospitalidade.

\section{Referências Bibliográficas}

BALANZÁ, I. e NADAL, M. 2003. Marketing e comercialização de produtos turísticos. São Paulo: Pioneira Thomson Learning.

BUTLER, R.W. 1980. The concept of a tourism area life cycle of evolution: implications for management of resources. The Canadian Geographer, v.24, n.1.

DICIONÁRIO HOUAISS DA LÍNGUA PORTUGUESA. 2001. Rio de Janeiro: Objetiva.

FONSECA, M. T. 2004. Tecnologias gerenciais de restaurantes. $3^{\mathrm{a}}$ Ed. São Paulo: SENAC.

KARLÖF, B. 1994. Conceitos básicos de administração - um guia prático. $2^{\mathrm{a}}$ edição. São Paulo: Nobel.

KOTLER, P. 2000. Administração de Marketing. São Paulo: Atlas.

KOTLER, P.; ARMSTRONG, G. 2003. Princípios de Marketing. $9^{\text {a }}$ ed. Rio de Janeiro: LTC.

MARICATO, P. M. 2004. Marketing para Bares e Restaurantes. Rio de Janeiro: Ed. SENAC Nacional.

MATTAR, F. N. 1997. Pesquisa de Marketing: Metodologia e Planejamento. 4a ed., São Paulo: Atlas, (vol 1).

MULLER, C.C. e WOODS, R. H. 1994. An expanded restaurant typology. Nova York: Cornell Quarterly - Cornell University, p. 27-36.

NOVAKOSKI, D. e FREIRE, R. 2005. Enogastronomia: a arte de harmonizer cardápios e vinhos. Rio de Janeiro: Senac Nacional.

PACHECO, A. O. 2006. Iniciação à enologia. $4^{\mathrm{a}}$ edição. São Paulo: Editora Senac São Paulo.

PERUSSI, R. F. 2008. Ações de marketing e comercialização. Em: BRAGA, D.C. Agências de viagens e turismo - práticas de mercado. Rio de Janeiro: Elsevier, p.89-103.

PORTER, M. E. 1986. Estratégia competitiva. Rio de Janeiro: Campus.

REEDY, J; SCHULLO, S.; ZIMMERMAN, K. 2001. Marketing eletrônico - a integração de recursos eletrônicos ao processo de marketing. Porto Alegre: Bookman. 
SEBRAE-Serviço Brasileiro de Apoio às Pequenas Empresas. SABOR \& GESTÃO. 2008. Boas idéias para alimentação fora do Lar. Brasília : SEBRAE: Futura.

SENAC. DN. 2006. Bares e restaurantes: gestão de pequenos negócios. Rio de Janeiro: SENAC Nacional.

SHAW, G. 2004. Culturas empresariais e pequenas empresas em Turismo. Em: LEW, a.; HALL, C.; WILLIAMS, A. Compêndio de Turismo. Lisboa: Instituto Piaget. Coleção Ciência e Técnica.

SWIFT, R. 2001. CRM - Customer relationship management: o revolucionário marketing de relacionamento com o cliente. $7^{\mathrm{a}}$ edição. Rio de Janeiro: Elsevier Editora.

Recebido em: 12/12/2009

Aprovado em: 07/04/2010 